\title{
Students' Perspectives about Nursing Education
}

\author{
Manal Zeinhom Ahmed ${ }^{1, *}$, Hasan Touama², Ahmad Rayan ${ }^{3}$ \\ ${ }^{1}$ Faculty of Nursing, Menofia University, Menofia, Egypt / Currently, Dean, Faculty of Nursing, Zarqa University, Zarqa, Jordan \\ ${ }^{2}$ Faculty of Economics and Administrative Sciences, Zarqa University, Zarqa, Jordan \\ ${ }^{3}$ Faculty of Nursing, Zarqa University, Zarqa, Jordan \\ *Corresponding author: Mahmed215@yahoo.com
}

Received February 04, 2015; Revised February 20, 2015; Accepted February 25, 2015

\begin{abstract}
Evaluation is becoming a necessary part of nursing education. Educators rely on evaluation in order to measure the quality of their teaching and to identify areas where improvement is needed in nursing education. The current study aims at determining nursing students' perspectives regarding their course content and teaching methodology. In addition, some suggestions for improvement of nursing curricula were obtained from the students. Mixed methods using concurrent triangulation design were used. Eleven theoretical nursing courses in the first semester of the academic year 2013/2014 were subjected to evaluation by students in which they were enrolled. The instrument used in the study was designed by the researchers; its validity and reliability were assured. Results indicated that content of courses and teaching methods were clear, comprehensive and well organized. Online materials and well prepared and organized instructors who use class time effectively were emphasized. On the contrary, a noisy environment was the most frequent aspect which negatively affected students' learning process.
\end{abstract}

Keywords: nursing education, teaching methods, course content, students' perspectives, undergraduate students

Cite This Article: Manal Zeinhom Ahmed, Hasan Touama, and Ahmad Rayan, "Students' Perspectives about Nursing Education." American Journal of Educational Research, vol. 3, no. 3 (2015): 288-291. doi: 10.12691/education-3-3-6.

\section{Introduction}

Evaluation is becoming a necessary part of nursing education. Many educationalists view evaluation as a mean of justifying their actions, a way of initiating selfassessment and developing personal evaluation techniques which are prerequisites for increasing self-confidence and personal growth on the part of faculty. Educators rely on evaluation in order to measure the quality of their teaching and to identify areas where improvement is needed in nursing education. In addition, evaluation of educational programs provides data on positive and negative aspects of these programs and supports learning experiences that have positive effects on students' growth and development [1].

Aims of curriculum evaluation may include program validation, curriculum improvement, meeting objectives, evaluation of innovation, and understanding the curriculum in whole or in part. Nursing education in Jordan has been developed over a relatively short period of time. Recently, the status of nursing is improving in Jordan as the number of students graduating from nursing programs is increasing. In addition, there is an emphasis on adopting new and more advanced roles for nurses in the future which require nurses to be well educated and trained [2]. This signifies a need for evaluation of quality of teaching in nursing education [3]. Moreover, some researchers found discrepancies in nursing textbooks and recommended that these textbooks need to be more consistent with more simplification of the ambiguous terms [4]. Therefore, the current study aims to determine students' perspectives related to content in nursing courses and teaching methodology. In addition, some suggestions for improvement of nursing curricula were obtained from the students.

Teaching methodology and students' characteristics were reported to be important determinants of success in nursing curricula [5]. In addition, curriculum design and instructor characteristics play an important role in forming students' attitudes towards nursing [6]. Moreover, the use of technology such as online materials and Web-enhanced learning opportunities incorporating online activities and content such as quizzes, videos, and virtual laboratories are reported to be highly effective from students' viewpoints [7].

\section{Methods}

Curriculum evaluation can be undertaken from a variety of perspectives and using a range of methods. In the early years of educational evaluation, the dominant approach was quantitative and borrowed its procedures from the scientific method of physical and biological sciences using experimentation. However, a combination of methodologies is recently considered an ideal approach to strengthen a study design in program evaluation [8]. Therefore, mixed methods research design was used in the current study. 
The evaluation framework utilized in this study was influenced by the work of a group of researchers who evaluated an online education program from the perspectives of new graduate nurses and includes five factors: course structure, course materials, technology, support services and assessment [9]. These five factors were the basis for the development of an instrument for data collection by the researchers in the current study.

Data were collected after official permission was approved from the Institutional Review Board of the university in which the study was conducted. Confidentiality and anonymity were granted for all study participants. Students' were informed that participation refusal would not negatively affect them in any way.

Mixed methods using concurrent triangulation design [10] were implemented to describe students' perspectives about content in nursing courses and teaching methodologies as well as suggestions for improvements.

Data were collected from Jordanian nursing students at the baccalaureate degree level during the first semester of the academic year 2013/2014 in one of the faculties of nursing in a private university in Jordan. All students who were enrolled in the eleven theoretical nursing courses and who agreed to participate in the study constituted the study sample. Prior to data collection, a brief explanation of the study was conducted to the participants.

An instrument was designed by the researchers which was influenced by the work of [9]. The instrument consists of three major parts; The first part consists of 9 questions concerning course content; the second part consists of 13 questions concerning teaching methodologies and teaching aids used in the course. The last part consists of three open ended questions concerning students' perspectives related to teaching methods that enhanced their understanding of the course, aspects of the course that impeded their understanding, and their suggestions for improvements. The instrument has a fivepoint Likert scale ranging from (1) strongly disagrees to (5) strongly agree. The scoring system of the instrument was calculated as follows: (1-2.33) was considered weak; (2.34-3.67) was considered moderate; and (3.68-5) was considered strong agreement. Reliability of the instrument was established using the Cronbach Alpha equation. The results of the Cronbach Alpha were: (0.83) for the whole instrument; (0.90) for the 9 items related to course content; (0.96) for the 13 items related to teaching methods; and (0.72) for the three open ended questions. Content validity of the instrument was assured by five experts in nursing education and curriculum evaluation. Guttman Split-half was used to test the stability of the responses.

For analysis purposes; quantitative data were coded and entered utilizing Statistical Package for Social Sciences (SPSS) version 18. In order to determine students' perspectives related to content of nursing courses, teaching methodology, and suggestions for improvement, quantitative data analysis utilized descriptive statistics such as mean and standard deviation were used. In addition, one-way ANOVA test was conducted to examine the differences between the means of students' responses about the questions related to the course content and instructors. Additionally, open ended questions (qualitative data) were read many times and themes were extracted. Finally, results of quantitative data were compared with qualitative data results to confirm the outcomes.

\section{Results and Discussion}

The current study explored students' perspectives related to nursing course content, teaching methodology, and suggestions for improvement. In order to obtain students' perspectives in evaluation of courses within a curriculum, both qualitative and quantitative data were gathered. The results of quantitative and qualitative data are presented and compared.

\subsection{Results of Quantitative Data}

\subsubsection{Students' Perspectives about Course Content}

As indicated in Table 1, students' perspectives regarding course content were strongly positive $(\mathrm{M}=4.21$, $\mathrm{SD}=0.68$ ). This suggests that students have a clear vision of course content. A similar result was supported by many researchers who reported that nursing students have positive attitudes toward the content of nursing curricula $[5,11,12,13]$.

Additionally, the results indicated that online materials were clear, comprehensive, and presented in a logical way with a mean score $(\mathrm{M}=4.31, \mathrm{SD}=0.89)$. This result was supported by [7] who examined graduating baccalaureate nursing students' perceptions of online educational approaches by incorporating online activities and content such as quizzes, videos, and virtual laboratories. The quality and usefulness of the online educational materials were rated fair to above average. However, reference [7] reported that satisfaction with online educational materials was associated with the level of information technology (IT) skills and perceived quality and usefulness of the internet materials. Moreover, reference [14] explored undergraduate nursing student feedback using qualitative and quantitative methods regarding course content and found that the online assessment item was one of the most positive aspects in the course.

Table 1. Means and Standard Deviations of Questions About Course Content

\begin{tabular}{|c|c|c|c|c|}
\hline Questions Related to the Course Content- Part One & Mean & SD & $\mathrm{F}$ & P-value \\
\hline 1. Online materials are clear, comprehensive, and presented in a logical way. & 4.31 & 0.89 & & \\
\hline 2. The course encourages me to be more knowledgeable and enhances my critical thinking. & 4.29 & 0.90 & & \\
\hline 3. The course is well organized and structured. & 4.27 & 0.84 & & \\
\hline 4. Course assignments meet the course objectives. & 4.25 & 0.84 & & \\
\hline 5. Exams reflect course content. & 4.23 & 0.93 & & \\
\hline 6. Assignments enhance better understanding of course content. & 4.20 & 0.86 & & \\
\hline 7. Grading system is clear and fair. & 4.18 & 0.91 & & \\
\hline 8. Students' responsibilities are clear in the course. & 4.16 & 0.94 & & \\
\hline 9. The course provides opportunities to learn from others. & 3.98 & 1.01 & & \\
\hline All questions & 4.21 & 0.68 & 13.06 & $0.000 * *$ \\
\hline
\end{tabular}


In addition, when students were asked if "the course provides opportunities to learn from others", they demonstrated strong agreement $(\mathrm{M}=3.98, \mathrm{SD}=1.01)$. This result had the lowest mean score among all questions related to course content. This result is inconsistent with [14] who explored undergraduate nursing student feedback about learning from others' experiences and found that group work and class room interaction were among the most positive aspects of the course. However, the researchers in the current study expected this result because the study sample was mainly made up of bridging students (students who had associate degrees in nursing and studying to get the baccalaureate degree in nursing). Most of bridging students working in a hospital and some of them come to class or clinical experiences after working the night shift in a hospital. They reported feeling tired from working and studying at the same time. In addition, they have a good clinical experience in hospitals and do not need to learn by sharing others. On the other hand, the regular students (students who are getting the baccalaureate degree in nursing after a high school degree) reported that they considered the experiences of bridging students' insignificant and they would interrupt the class when bridging students expressed their experiences. They may prefer to read from their textbook which is considered their official way of learning. Therefore, students considered class discussion and participation as noisy teaching-learning environment because they are a heterogeneous group.

\subsubsection{Students' perspectives about the Instructor}

Table 2 demonstrated that students' perspectives about instructors' teaching methods were strongly positive $(n=231, M=4.03, S D=0.91)$. This result indicates a high agreement among all students about the instructors' methods of teaching.

The highest mean score $(\mathrm{M}=4.13$, $\mathrm{SD}=0.91)$ was for "the instructor is well prepared, organized, and uses class time effectively". While "the instructor makes difficult materials understandable" had the lowest mean score ( $\mathrm{M}$ $=3.74, \mathrm{SD}=1.23$ ) among all questions. In the same context, reference [14] explored undergraduate nursing student feedback using qualitative and quantitative feedback and found that the teaching staff was one of the most positive aspects of the course. These results were very valuable because students who perceived their instructors as more credible were reported to be more knowledgeable about their courses [6].

\subsection{Results of Qualitative Data}

The qualitative data demonstrated that the most frequently positive aspects enhanced the teaching-learning process reported by students were the use of online materials and class participation. The least negative aspect affected the teaching-learning process reported by students was unavailability of handouts. The data indicated that handouts are an important part of course materials. While they may be available online, it is also important for students to have the actual materials in hand $[12,13,15]$. Additionally, the majority of students are working and may lack the time to go to the library or make internet searches. The qualitative data also indicated that the most frequently negative aspect affected the teaching-learning process reported by students was noisy environment. The most frequent suggestion for improving the teachinglearning process reported by students was improving the teaching-learning environment by decreasing noise. Different studies focused on the importance of teaching environment to motivate students to learn by decreasing background noise, and visual distractions, controlling room temperature, and providing comfort seating [16,17]. However, in this study, most of students were bridges and coming to the classroom very tired, this could be the reason for being very sensitive for noise and distraction.

Table 2. Means and Standard Deviations of Questions Related to Instructors

\begin{tabular}{|c|c|c|c|c|}
\hline Questions related to the instructor-Part Two & Mean & SD & $\mathrm{F}$ & P-value \\
\hline 1. Instructor is well prepared, organized, and uses class time effectively. & 4.13 & 1.04 & & \\
\hline 2. Instructor expresses ideas clearly. & 4.12 & 1.06 & & \\
\hline 3. Instructor answers students' questions. & 4.11 & 1.09 & & \\
\hline 4. Instructor uses teaching methods that help to understand and to apply knowledge to the practice of nursing. & 4.11 & 1.04 & & \\
\hline 5. Instructor stimulates attention to the topic. & 4.10 & 1.05 & & \\
\hline 6. Instructor provides feedback on student academic performance. & 4.08 & 1.05 & & \\
\hline 7. Instructor is enthusiastic and has confidence about the topic being discussed. & 4.06 & 1.11 & & \\
\hline 8. Instructor treats students with respect and justice. & 4.03 & 1.12 & & \\
\hline 9. Instructor seems concerned about students' learning. & 4.03 & 1.03 & & \\
\hline 10. Instructor encourages students to ask questions and participate in the class. & 3.98 & 1.16 & & \\
\hline 11. Instructor successfully uses online learning system to promote learning. & 3.95 & 1.18 & & \\
\hline 12. Instructor is available for consultation at office hours. & 3.93 & 1.19 & & \\
\hline 13. Instructor makes difficult materials understandable. & 3.74 & 1.23 & & \\
\hline All questions & 4.03 & 0.91 & 28.4 & $0.000^{* *}$ \\
\hline
\end{tabular}

\subsection{Comparison of Qualitative and Quantitative Data}

The qualitative data demonstrated that the most frequently positive aspects which enhanced the teachinglearning process reported by students were the use of online materials (including audiovisual materials and assignments) and class participation. These results support the quantitative data shown in (Table 3) and confirmed previously in the first question in Table 1 . The most frequently negative aspects that affected the teachinglearning process reported by students were a noisy environment and interruptions from students that support the quantitative data shown in (Table 3). 
Table 3. Aspects That Positively and Negatively Affected the Teaching-Learning Process

\begin{tabular}{|c|c|c|}
\hline Teaching aids & Frequency & $\%$ \\
\hline Online materials (including audiovisual materials and assignments). & 117 & 95.9 \\
\hline Class participation, white board and others. & 13 & 10.7 \\
\hline \multicolumn{3}{|l|}{ Negative Aspects ( $\mathrm{n}=79$ responses)* } \\
\hline Teaching aids & Frequency & $\%$ \\
\hline Noisy environment. & 19 & 24.1 \\
\hline Interruptions from students. & 15 & 19 \\
\hline Late theoretical classes after exhausting clinical training. & 7 & 8.9 \\
\hline
\end{tabular}

*Some students mentioned more than one aspect

\section{Conclusion}

Students strongly agreed that course' content delivered using a variety of teaching methods and aids have facilitated the learning process. A noisy environment and students' interruptions were issues that impeded understanding of course content. Therefore, Instructors should carefully consider the aspects that positively or negatively affect teaching/learning process. This study also concluded that actively identifying appropriate classroom participation would improve the teachinglearning environment.

\section{References}

[1] Stavropoulou, A. and Kelesi, M, "Concepts and methods of evaluation in nursing education," Health Science Journal, 6 (1). 11-23.2012.

[2] Rayan, A., and Dadoul, A, "Decrease the length of hospital stay in depressed cancer patients: Nurses should be involved," American Journal of Nursing Research, 3 (1). 4-7. 2015.

[3] Zahran, Z, "Nurse education in Jordan: history and development," International Nursing Review, 2 (3). 274-280. 2011.

[4] Ahmad, M., Saleh, A., Rayan, A., Bdair, I. A., Batarseh, K., Abuadas, F., ... and Abu-Abboud, N, "Web-based research using Delphi methodology to explore the discrepancy in qualitative research," International Journal of Nursing and Health Science, 1 (6). 60-68. 2014.

[5] Gough, K., and Happell, B, "Undergraduate nursing students' attitude to mental health nursing: A cluster analysis approach," Journal of Clinical Nursing, 18 (22). 3155-3164. 2009.

[6] Cordero, E.D., Israel, T., White, S. and Park, Y.S, "Impact of instructor and course characteristics on the effectiveness of curriculum infusion," Journal of American College Health, 59 (2). 75-81. 2010.

[7] Creedy, D., Mitchell, M., Seaton,-Sykes, P., Cooke, M., Patterson, E., and Purcell, C, "Evaluating a Web enhanced bachelor of nursing curriculum: Prespectives of third-year students," Journal of Nursing Education. 46 (10). 460-467. 2007.

[8] Roxburgh, M., Watson, R., Holland, K., Johnson, M., Lauder, W. and Topping, K, "A review of curriculum evaluation in united kingdom nursing education," Nurse Education Today, 28, 881889.2008.

[9] Karaman, S., Kucuk, S., \&Aydemir, M, "Evaluation of an online continuing education program from the perspective of new graduate nurses," Nurse Education Today, 34 (5). 836-841. 2014.

[10] Cresswell, J. W., and Clark, V. L. P, Designing and Conducting Mixed Methods Research. Thousand Oaks, CA: Sage. 2007.

[11] Numminen, O., van der Arend, A. and Leino-Kilpi, H, " Nurse educators' and nursing students' perspectives on teaching codes of ethics," Nursing Ethics, 16 (1). 69-82. 2009.

[12] Rice, B., Gallagher, P., McKenna, N., Traynor, M. and McNulty, $\mathrm{T}$, "The immediate life support course: implementation into an undergraduate nursing programme,". Nursing in Critical Care, 146. 279-316. 2009.

[13] Wallace, M., Campbell, S., Grossman, S.C., Shea, J.M., Lange, J.W. and Quell, T.T," Integrating spirituality into undergraduate nursing curricula,: International Journal of Nursing Education Scholarship. 5. 1-13. 2008.

[14] Halcomb, E. J., and Peters, K," Nursing student feedback on undergraduate research education: Implications for teaching and learning," Contemporary Nurse, 33 (1). 59-68. 2009.

[15] Birks, M., Cant, R., Al-Motleq, M., and Jones, J, “I don’t want to become a scientist. Understanding nursing students' percieved value of course content", Australian Journal of Advanced Nursding. 28 (4). 20-27. 2011.

[16] Hutchinson L, "Educational environment," British Medical Journal, 326 (7393), 810-812.

[17] Yang, Z., Becerik-Gerber, B., and Mino, " A study on student perceptions of higher education classrooms: Impact of classroom attributes on student satisfaction and performance, Building and Environment, 70, 171-188. 2013. 